\title{
WRITING CONVERSATIONS: FOSTERING METALINGUISTIC DISCUSSION ABOUT WRITING
}

Debra Myhill, Susan Jones and Anthony Wilson

University of Exeter, UK

\section{ABSTRACT:}

This paper draws on data from a national study, involving an experimental intervention with 54 schools across the country, in which teachers were mentored in a pedagogical approach involving explicit attention to grammatical choices and which advocated high-level metalinguistic discussion about textual choices. The research focused upon primary children aged 10-11, and in addition to statistical analysis of outcome measures, 53 lesson observations were undertaken to investigate the nature of the metalinguistic discussion. The data were analysed inductively, following the constant comparison method, with an initial stage of open coding, followed by axial coding which clustered the data into thematic groups. The analysis demonstrates the potential of metalinguistic talk in supporting young writers' understanding of how to shape meaning in texts and the decision-making choices available to them. It signals the importance of teachers' management of metalinguistic conversations, but also the role that teachers' grammatical subject knowledge plays in enabling or constraining metalinguistic talk. The study highlights the importance of dialogic classroom talk if students are to develop knowledge about language, to become metalinguistically aware, and to take ownership of metalinguistic decision-making when writing. 


\section{INTRODUCTION}

This article focuses upon how students develop metalinguistic understanding about writing, and particularly how the teachers' management of classroom conversations about writing facilitates the development of that understanding. At the heart of this is the need for dialogic teaching in which the teacher opens up, sustains and extends conversations about writing which support students' metalinguistic learning about writing and language choices. There is, of course, a substantial and long-standing body of research on the importance of talk in the process of learning, including Britton's seminal claim that 'reading and writing float on a sea of talk' (Britton 1983, 11). More recently, sociocultural studies into dialogic talk (Alexander 2008; Mercer 2000; Mercer and Littleton 2007; Wegerif 2011) have emphasised the relationship between talking and thinking, and the importance of the teacher's skill in orchestrating dialogic interaction in the classroom. At the same time, research in writing has signalled the influence of talk, especially early oral development, on writing (Shanahan 2006) but there has been very little research into how talk develops students' understanding of writing, and how to write. This paper brings together these conceptual strands to examine how teachers' management of talk during the teaching of writing fosters students' metalinguistic understanding about writing. It takes as its empirical base a national study involving 54 primary schools who were mentored in implementing a pedagogical intervention which used the theoretical thinking about talk for learning as a tool for developing metalinguistic understanding. The paper extends our theoretical understanding of metalinguistic talk about writing by signalling the importance of teachers' management of metalinguistic conversations, and the role that teachers' grammatical subject knowledge plays in enabling or constraining metalinguistic talk. The study highlights the importance of dialogic metalinguistic classroom talk if students are to develop knowledge about language, to become metalinguistically aware, and to take ownership of metalinguistic decision-making when writing.

\section{CONCEPTUAL FRAMEWORK}

\section{Linguistic decision-making in writing}

Kellogg (2008) argues that all writers must make decisions about the texts they are writing, and those decisions occur at multiple levels, including ideational, lexical, syntactical, textual and presentational levels. Crucial to the argument in this paper, linguistic choices are not merely mechanistic or technical choices related to superficial grammatical accuracy or spelling, but a fundamental part of the writing process itself, shaping ideas and content to suit the intended rhetorical purpose. Micciche $(2004,719)$ maintains that:

The grammatical choices we make, including pronoun use, active or passive verb constructions, and sentence patterns - represent relations between writers and the world they live in. Word choice and sentence structure are an expression of the way we attend to the words of others, the way we position ourselves in relation to others. In this sense, writing involves cognitive skills at the level of idea development and at the sentence level.

Our interest is in this concept of grammatical choice in writing, which counterpoints strongly with traditionalist views of grammar as principally concerned with rules and compliance. Carter and McCarthy $(2006,7)$ helpfully distinguish between the grammar of structure, which describes how language is organised as a system, and the grammar of choice, which is more concerned with how grammatical choices make meaning. For example, consider Dickens' description of Magwitch's first appearance in Great Expectations:

A fearful man, all in coarse grey, with a great iron on his leg. A man with no hat, and with broken shoes, and with an old rag tied round his head. A man who had been soaked in water, 
and smothered in mud, and lamed by stones, and cut by flints, and stung by nettles, and torn by briars; who limped and shivered, and glared and growled; and whose teeth chattered in his head as he seized me by the chin.

Here Dickens uses minor sentences, with no main verb, in the form of three noun phrases, headed by 'man' to present Magwitch to the reader. The choice of visual detail offered in the prepositional phrases (with no hat; with broken shoes, with an old rag round his head) suggests he is on the margins of society, and the detail of the 'great iron on his leg' invites the reader to infer he is an escaped prisoner. The third, very extended noun phrase, uses the passive voice to present a character who, whilst 'fearful', is also a victim unpleasant things have happened to him, alongside the unpleasant things we infer he has done. The counterpointing of verbs which depict his discomfort, or vulnerability, (limped; shivered; chattered) with verbs which suggest aggression (glared; growled; seized) emphasise further Dickens' initial presentation of Magwitch as both victim and aggressor, a presentation sustained throughout the novel. Here grammar and meaning are symbiotically related, and the linguistic choices Dickens makes are fundamental to the narrative development.

Of course, this idea of linguistic decision-making begs the critical question of whether these choices are conscious or unconscious, explicit or implicit. Galbraith (1999) contended that competent writing involves a dual process, with one system rule-based, controlled, and conscious (knowledge transforming) and the other associative, automatic, and unconscious (knowledge constituting). However, he does not elaborate on how these two systems are distinguished, how they interact, or what part linguistic choice plays in either system. Becker $(2006,35)$ differentiates between 'linguistic resources' and 'rhetorical strategies'. When linguistic resources are expanded, they support greater fluency in writing as lexical and syntactical choices are automated, thus freeing up working memory. The use of rhetorical strategies supports those choices which address the author's rhetorical intentions. Becker therefore appears to separate linguistic decision-making from rhetorical decision-making. Galbraith's reference to a rule-based system, and Becker's notion of linguistic resources may point to a common tendency in cognitive psychology to see the production of text as a purely rule-bound activity. The text production stage in the writing process is described by Negro and Chanquoy $(2005,106)$ as a process of formulating ideas in words, which need to 'ordered into grammatically and syntactically correct sentences to form a cohesive text', a process which becomes automated because it involves 'mainly the application of fixed rules'. But writing is not simply text production - it is a more complex process of text creation, shaped by the interaction of the writer's own sense of intention, awareness of the needs of the implied reader, and the social expectations of that kind of writing. We would argue, therefore, that automated, or implicit, choices reflect competency in what Carter and McCarthy (2006) refer to as the grammar of structure, whilst rhetorical strategies, or explicit choices, reflect the grammar of choice and meaning-making. It is these explicit choices with which this paper is concerned. Further, we would argue that automated, implicit choices are linguistic, whilst rhetorical, explicit choices are metalinguistic.

\section{Metalinguistic understanding in writing:}

Accepting that metalinguistic choices are explicit, our interest is in how teachers' dialogues in the classroom facilitate the development of metalinguistic understanding about writing. First, however, it is important to clarify conceptual thinking about metalinguistic understanding, as 'there is no consensus regarding the precise domain of activities which properly may be called metalinguistic' (Bialystok and Ryan 1985, 229). The adjective 'metalinguistic' variously, and sometimes indiscriminately, precedes 'understanding', 'knowledge', 'awareness', 'behaviour', 'activity' and 'development'. Moreover, the conceptualisation of metalinguistic activity differs subtly between psychology and linguistics, a difference summarised by Wang and Wang $(2013,47)$ as 'language about language' in linguistics, but 'language 
cognition' in psychology. Nonetheless, there is general agreement that metalinguistic understanding relates to reflection on language and its use, and that it is activity which is intentional and controlling (Bialystok 1987; Gombert 1992; Wilkinson et al. 1984). Reflecting our own interdisciplinary perspective on writing, integrating psychological, linguistic and sociocultural lenses, we have defined metalinguistic understanding as 'the explicit bringing into consciousness of an attention to language as an artifact, and the conscious monitoring and manipulation of language to create desired meanings grounded in socially shared understandings' (Myhill 2011, 250).

Theoretical and empirical attention to metalinguistic understanding has historically focused more on oral language development, bilingual learning, and early writing development. In the context of writers whose development takes them beyond mastery of transcription and orthography, metalinguistic understanding becomes more concerned with decision-making in writing, than with writing fluency or system mastery. For a detailed analysis of the conceptualisation of metalinguistic understanding in writing, see Myhill and Jones (2015). However, for this paper we are particularly interested in how metalinguistic understanding supports the choices writers make and how it enables 'control over grammar and lexis' so that writers 'produce the nuances we need to realise the meaning potential that language affords us' (Janks 2009, 131). A core element of metalinguistic understanding is that it is verbalisable. Roehr $(2008,179)$ sees the distinction between non-verbalisable and verbalisable linguistic knowledge as the distinction between implicit linguistic knowledge and explicit metalinguistic knowledge. Thus talk becomes a key mechanism through which metalinguistic understanding in writing is developed and articulated.

\section{The role of the teacher in developing metalinguistic understanding of writing}

If talk is a key mechanism for developing metalinguistic understanding about writing, the role of the teacher in setting up interactions in the classroom which build and extend that understanding is critical. Children's development as writers is socially shaped through their oral language experiences (Bruner 1983; Corden 2000) and through their experiences as readers (Barrs and Cork 2001). To this extent, it parallels learning to talk in that it is dependent upon meaningful social interactions in authentic contexts and develops naturally. But writing differs from talk in that children also have to be taught to write through specific pedagogic interventions. Although some children do learn through absorbing patterns from their reading experiences, most children need explicit teaching of these things. Young writers need to be supported in developing awareness of how linguistic choices in writing alter how the text shapes meaning. For example, in speech, adjectives are predominantly in an attributive position, but can be positioned predicatively in writing for particular emphasis, as Michael Morpurgo $(1994,17)$ does in Arthur, High King of Britain:

She died when I was just twelve years old. As she lay on her deathbed, her eyes open and unseeing, I reached out to touch her cheek for the last time.

A retelling of this incident in speech would be more likely to be constructed as 'Her eyes were open and unseeing' or as 'her unseeing open eyes', rather than the post-modification used here, which draws attention in a literary way to the adjectival description. Developing this kind of metalinguistic understanding through dialogic conversations is very much the role of the teacher, helping the learners to make 'writerly' decisions.

Yet we know that, despite the strong emphasis on the value of dialogic teaching, genuine dialogic interactions are not common features of teaching in many classrooms, at least in the UK (Howe and Abedin 2013). The shift from what Skidmore (2000) calls 'pedagogical dialogue' to 'dialogic pedagogy' seems to be a hard one to achieve. In this paper, the dialogical pedagogy we are interested in relates to teacher- 
student dialogic interactions, rather than peer-to-peer interactions, and particularly in the teacher's management of these interactions to build metalinguistic understanding. Alexander (2008) characterises dialogic interactions as those where students ask questions, explain their points of view, and comment on each other's ideas, but more recent research has extended thinking on dialogic teaching to emphasise: the importance of supporting learners in articulating and justifying their own thinking (Chinn, O'Donnell, and Jinks 2000; Gillies 2015); the structures of constructive educational dialogue (Littleton and Howe 2010); and providing feedback that stimulates further exploration (Reznitskaya et al. 2009). However, research in dialogic teaching has often focused on Maths and Science teaching, or open-ended discussions in primary schools, and there is a substantial gap in empirical attention to how dialogic teaching supports language learning, and especially metalinguistic learning about writing.

At the same time, the teaching of writing and teachers' pedagogical practices are influenced by broader contextual factors. External constraints, such as those exerted by curriculum or examination expectations, shape classroom discourses around writing, and shape what children learn about being a writer. In a classroom, writing occurs within a community of practice in which the teacher is a powerful mediator: indeed, Prior $(2006,58)$ maintains that teachers are, in effect, co-authors in the writing process, and arguably the dominant co-author, as typically they determine the task, the topic, the time for writing, and judge its quality. And teachers' own pedagogical and subject knowledge influences how they teach writing. In the context of metalinguistic understanding about writing, limitations in teachers' grammatical knowledge mediate their pedagogical actions in the classroom (Myhill, Jones, and Watson 2013). This study, accordingly, set out to investigate how teachers enable and develop students' metalinguistic understanding of grammatical choices in writing through dialogic classroom talk.

\section{METHODOLOGY}

The data on which this article reports is from a study funded by the Educational Endowment Fund, which involved a cluster randomised controlled trial, testing the effects of an intervention which embedded grammar within the teaching of writing. The sample was formed of fifty-four primary schools from the South-West of England, London, West Midlands and Sheffield. In each school, two classes $(n=108)$ of students aged 10-11 were involved, half as intervention groups and half as comparison groups.

\section{The intervention:}

The intervention drew on research from earlier studies (Myhill et al. 2012; Myhill et al. 2013; Jones et al 2013a) which had demonstrated a beneficial effect on students' written outcomes. These had been conducted with secondary-aged students, whereas the intervention for this study was for primary students. The design of the intervention is founded upon a theorisation of grammar as functionally-oriented and a resource for meaning-making. The pedagogic focus, therefore, is not upon grammatical accuracy but upon grammatical choice, intended to help writers understand both the choices that published authors make in their texts, and the repertoire of choices that are available to them as writers themselves. The intervention was underpinned by a set of pedagogic principles (see Jones et al. 2013b, for a fuller explanation), and the intervention teachers attended three Continuing Professional Development (CPD) sessions to help them understand these principles.

Two of these principles are particularly relevant to this article. Firstly, the teaching intervention emphasised the making of connections between a grammatical point and its meaning-making effect in writing, thus avoiding decontextualized attention to grammar, and focusing attention on grammar-writing links which were relevant to the learning. For example, children looked at how character description can be achieved through well-chosen noun phrases. The Intervention teaching materials focused on the writing of fictional narrative, based on a book by Michael Morpurgo (Arthur, High King of Britain) and a BBC TV 
series (Merlin). The learning objectives and grammar focuses are set out in Table1 below, illustrating how the link between grammatical choices and their potential meaning-making effects in writing narrative fiction.

Table 1: the learning objectives and grammar focuses for the intervention teaching unit

\begin{tabular}{|c|c|}
\hline LEARNING OBJECTIVES & GRAMMAR FOCUSES \\
\hline $\begin{array}{l}\text { - Make links between students' reading and } \\
\text { viewing of fiction and the choices they make } \\
\text { as writers } \\
\text { - Understand possible narrative structures and } \\
\text { the idea of a narrative introduction, } \\
\text { problem, crisis, and resolution } \\
\text { - Understand how authors describe characters } \\
\text { - Understand how writers vary sentences for a } \\
\text { - Uniterly purpose } \\
\text { - Understand how punctuation marks } \\
\text { - } \text { mentence boundaries and signals nuances in } \\
\text { - } \text { explerstand how to manage description and } \\
\text { Know how to shape, craft, edit and evaluate } \\
\text { own fictional narrative writing }\end{array}$ & $\begin{array}{l}\text { - Consolidation of understanding of sentence boundaries } \\
\text { and accurate use in writing } \\
\text { - Consolidation of capitalisation of Proper Nouns for } \\
\text { characters and places } \\
\text { of characters } \\
\text { - How noun phrases, especially with post-modification, } \\
\text { generate descriptive detail of characters } \\
\text { - How verbs can establish character by showing what } \\
\text { characters do } \\
\text { - How subject verb inversion in sentences alters the } \\
\text { - Howphasis in a sentence for plot effects } \\
\text { the narration of an episode in a plot } \\
\text { - How short sentences can create emphasis or } \\
\text { anticipation in developing a plotline }\end{array}$ \\
\hline
\end{tabular}

Secondly, the intervention emphasised the importance of opportunities for high-quality dialogic discussion, both between teachers and students, and between peers, and encouraged teachers to foster discussion about grammatical choices and effects. In the context of a national system of high-stakes writing assessments, which has had an unintended consequence of promoting very formulaic, 'toolkit' approaches to writing with checklists of what different kinds of writing 'must' contain, the emphasis on dialogic talk was directed at countering the prevailing tendency to teach set patterns for writing, but instead to open up leaners' understanding of the repertoire of different possibilities from which they can choose. In this way the intervention attempted to move teachers, in line with Skidmore's (2006) thinking from a rather monolithic pedagogical dialogue where the teachers owned and controlled the knowledge to a more dialogic pedagogy, where teachers skilfully gave ownership to the writers and opened up their metalinguistic understanding of the linguistic possibilities available. In particular, the activities in the intervention materials and the CPD emphasised the importance of: supporting learners in articulating their own thinking (Gillies 2015; Gillies et al. 2012); and providing feedback that stimulates further exploration (Reznitskaya et al. 2009). In the CPD sessions, teachers were given opportunities to consider how a more dialogic approach to talk about writing might include talk which:

$>$ Fosters the justification of language choices made

$>$ Is prepared to challenge cliche or forced, overdone writing

$>$ Supports writers to make links between the grammar feature and its effect in shaping meaning in writing

$>$ Generates questions and pursue misunderstandings

$>$ Encourages experimentation and language play

$>$ is prepared to discuss constructively why some attempts are less successful 
The teaching materials written for the intervention group actively attempted to support teachers in this kind of dialogic discussion by building in talk opportunities which actively created awareness that choices were available, and which discouraged a 'right answer' formulaic approach.

\section{Lesson observations}

This article reports on the qualitative data captured through lesson observations conducted during the implementation of the intervention. Each school in the project, bar one, was observed once in the four week intervention period, using a semi-structured observation schedule (Appendix A). This observation schedule was designed to capture both how teachers used the intervention teaching materials, and how students responded to them, including evidence of transfer of the learning focus into their writing. The observation was also used to establish a fidelity score for the statistical analysis. Each lesson was also audio-recorded as additional data to support the observation, and to allow further post-hoc checking or elaboration, if needed. Prior to data analysis, the audio data was scrutinised and transcriptions made of interaction sequences which revealed how the intervention was being implemented. A transcript was then created which incorporated the lesson observation with transcribed data from the audio capture to form the document for data analysis.

\section{Data analysis}

The data was coded inductively by four coders, using Nvivo software, and following an initial open coding process, attributing codes to segments of interaction, with subsequent axial coding, clustering the codes into broader themes. The research team followed the constant comparison approach, iteratively rechecking and re-labelling to refine the focus and consistency of coding. Firstly, each coder independently coded the same transcript, and the research team then came together to discuss similarities and differences in codes developed, and to agree initial codes common to all coders. This process was then repeated, but with each coder coding a different transcript, leading to a further set of codes agreed by all. The four coders then independently coded five transcripts each, including re-coding those coded earlier, using the agreed codes as a starting-point but still creating new codes where relevant. At this point, the coders met again to compare the open coding so far, following the process outlined below:

checking that the coding of the initial agreed codes was consistent across the four coders;

$\square$ checking and agreeing new codes;

merging codes which were very similar;

splitting codes where it became evident two codes were needed;

$\square$ refining code names and definitions.

During this coding meeting, it became evident that thematic clusters were already apparent, so it was agreed to cluster the codes agreed thus far under five axial codes: Connections between Grammar and Writing; Discussion; Subject Knowledge; Student Understanding; and Evidence in Writing. The coding team then re-checked all coding undertaken previously, and continued to code the remaining transcripts. A final meeting of the coding team repeated the checking process outlined above. The full set of final codes is included in Appendix B.

\section{THE FINDINGS}

This paper reports on the data which was categorised within the axial code, Discussion, which focused on the classroom interaction between teacher and students, or between students. These interactions either related to discussions about the linguistic choices made by Michael Morpurgo in Arthur, High King of Britain, or the linguistic choices the students were making in drafts of their own 'Merlin' stories. The coding 
under the Discussion theme included six codes which characterised the nature of the classroom metalinguistic talk. These six codes and their definitions are outlined in Table 2 below.

Table 2: the codes categorised under the Discussion theme.

\begin{tabular}{|l|l|}
\hline Code & Definition \\
\hline Skilful management & $\begin{array}{l}\text { The teacher manages the discussion skilfully across a sequence of } \\
\text { interactions, including through refocusing, to draw out understanding }\end{array}$ \\
\hline Clear focus & The learning purpose for the discussion is clear \\
\hline Justification of choices & $\begin{array}{l}\text { The teacher pushes students to explain and justify choices, including } \\
\text { challenging inappropriate choices }\end{array}$ \\
\hline Unclear focus & The learning purpose for the discussion is not clear, or is confused \\
\hline Too much teacher talk & $\begin{array}{l}\text { An episode is dominated by teacher talk, including by labouring a point for } \\
\text { too long }\end{array}$ \\
\hline $\begin{array}{l}\text { Missed opportunity for } \\
\text { learning }\end{array}$ & $\begin{array}{l}\text { The teacher misses a valuable opportunity to explore a grammar-writing } \\
\text { connection }\end{array}$ \\
\hline
\end{tabular}

379 data segments were coded under the Discussion theme, and table 3 illustrates how that coding was distributed. This shows how many of the 53 teachers were represented in each of these codes, and how often a data segment was categorised under this code. The table also shows what percentage of all the Discussion data segments were allocated to each code. Using our original theorisations of dialogic talk, particularly the emphasis on supporting learners in articulating their own thinking (Gillies 2015; Gillies et al. 2012); and providing feedback that stimulates further exploration (Reznitskaya et al. 2009), the six codes were divided into two groups, representing examples of dialogic or less dialogic metalinguistic talk. The numbers are included for purposes of transparency, rather than for any robust statistical analysis. Nonetheless, the data show that across the whole sample, the metalinguistic discussion is fairly evenly split between dialogic and less dialogic talk, albeit with a small advantage for dialogic talk. Given that one of the key pedagogical principles underpinning the intervention was the use of high-quality dialogic talk about language choices, this is a significant finding, because it highlights both the capacity of primary teachers to lead dialogic metalinguistic discussion, and the challenges that some teachers face in this respect. This will be developed further later in this paper.

Table 3: Distribution pattern of the Discussion theme codes

\begin{tabular}{|l|c|c|c|c|}
\hline & No of Teachers & Code frequency & \% of all & \\
\hline Less dialogic metalinguistic talk & & & & \\
\hline Missed opportunity for learning & 33 & 88 & $23 \%$ & \\
\hline Too much teacher talk & 17 & 50 & $17 \%$ & \\
\hline Unclear focus & 13 & 40 & $11 \%$ & $47 \%$ \\
\hline Dialogic metalinguistic talk & & & & \\
\hline Clear focus & 29 & 79 & $21 \%$ & \\
\hline Justification of choices & 24 & 48 & $13 \%$ & \\
\hline Skilful management & 29 & 74 & $20 \%$ & $53 \%$ \\
\hline
\end{tabular}

An analysis of how these codes represented the 53 teachers (Table 4) indicated that half of the teachers 
( $n=27)$ led metalinguistic talk which was coded both with examples of dialogic and less dialogic metalinguistic talk, a reminder that the data is not characterising teachers as 'dialogic' or 'less dialogic' but characterising the talk. Clearly, for many teachers, the quality of metalinguistic talk is variable across a lesson. 16 teachers had all of their classroom talk coded under the dialogic codes, whilst 10 were exclusively coded under the less dialogic codes. It is important to remember that, although high-quality classroom talk has been promoted by the English curriculum for some time, the precise metalinguistic talk advocated in this intervention, discussing how grammar shapes meaning in writing, was not familiar to teachers and some of the variability within a lesson may have been due to this.

Table 4: showing how the codes were distributed across the teacher sample

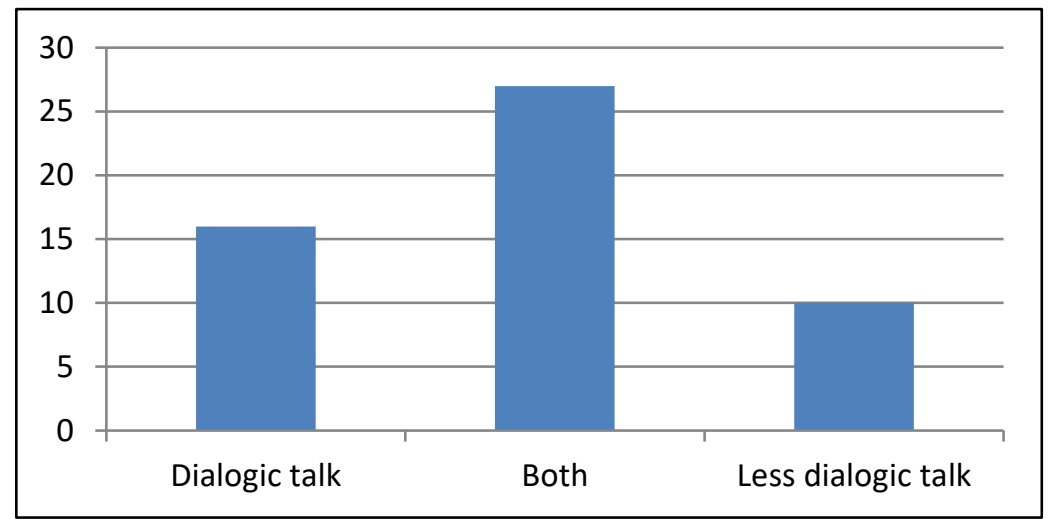

\section{Dialogic Metalinguistic Discussion}

\section{Skilful management}

Data segments categorised under this code reflect those discussion moments when the teacher manages a stretch a classroom discourse skilfully, enabling students to develop their thinking and their understanding. In the episode below, the class have been considering how well-chosen nouns, verbs and adjectives can convey character effectively, using the 'show not tell' technique of inviting the reader to infer character from what they are shown. The class have been discussing Morpurgo's description of Merlin's face, as 'parchment-silver and etched with age', and what that suggests about his character. From this, in one interaction sequence, the teacher manages a consideration of a child's verb choice of 'advise', and how this verb choice can convey something about character.

Teacher: Have you got one (verb) that I haven't already written down?

Student: Advised

Teacher: If you can advise somebody, what does that say about your character?

Student: They're telling them something

Teacher: Ok, that's what advised means but if you're going to someone for advice, would you go to a three year old?

Student: No

Teacher: So what kind of person would you go to for advice?

Student: An old man

Teacher: Someone who has a lot of...

Student: Knowledge

Student: Life

Student: Wisdom

Teacher: Good. So you'll be looking for someone with knowledge, experience etc. 
In this episode, the teacher takes a student's own writing as the trigger for the subsequent discussion, and redirects the students' focus from a rather literal interpretation of the verb 'advise' to one which recognises that being a person who gives advice suggests something about who you are. She also creates space for three students to contribute one after another, breaking the teacher-student-teacher-student rhythm of much classroom interaction.

A different teacher, teaching the same lesson in the intervention, also skilfully manages one student's understanding of how word choice can infer character in a discussion about Morpurgo's depiction of Guinevere:

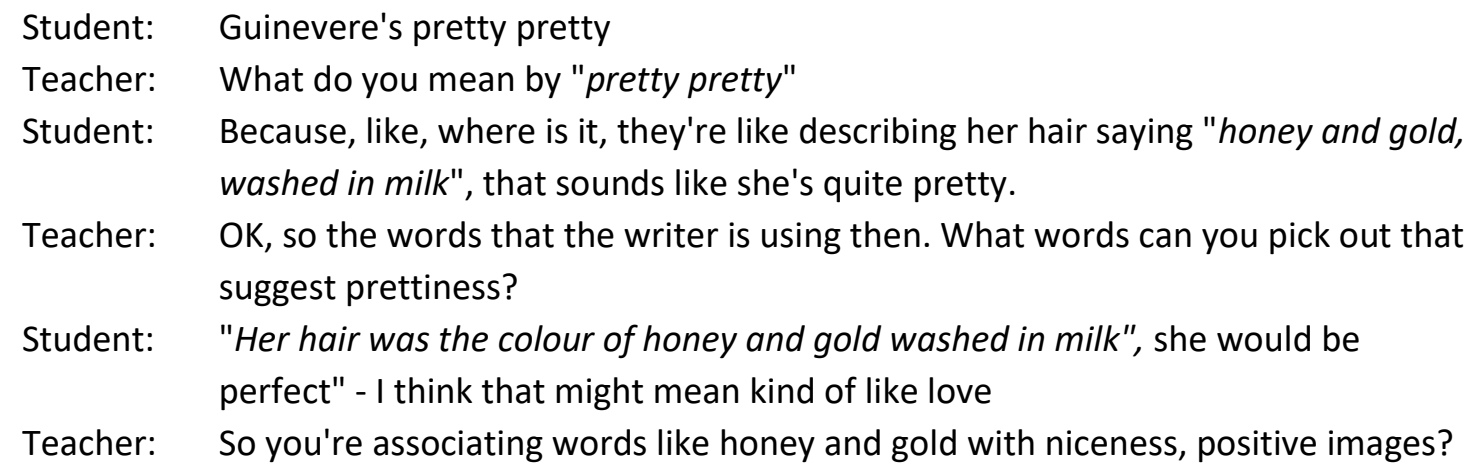

Here the teacher does not accept the student's first response, but instead invites her to explain what she means. Then, when the student locates some of the descriptions that link to her point, the teacher focuses the student's attention on considering which word choices suggest prettiness. The student gives the full textual reference, and then elaborates on her initial point, moving from mere prettiness to the sense that the character description is of someone who is perfect, and who might be someone other people love. The teacher concludes the interaction by making explicit how the word associations work (though she might have drawn out more the student's point about love), and the sequence has given this student the opportunity to elaborate and focus her understanding.

Other examples of skilful management of metalinguistic talk occurred when the teacher intervened in a group or individual activity to bring something to the attention of the whole class. In the episode below, the students were working on a task looking at noun phrases for character description (a lady, dark-haired and beautiful, wearing a gown of wine-red; her long fingers extended, and her eyes, wide and intense) and the teacher realised there was some grammatical confusion about nouns and verbs. The teacher pauses the group task to address this confusion:

Teacher: $\quad$ OK, a few misunderstandings, some people are having trouble deciding what is the noun and what were the adjectives that went with the nouns for the body parts. Let's go through one or two examples quickly so that we're on the right track. When we talk about Nimueh, what were the names of the body parts that were mentioned?

Student: $\quad$ eyes wide and intense

Teacher: So which one is the noun?

Student: eyes

Teacher: Good, so that should have been in the first box. And how did it describe the eyes?

Student: $\quad$ wide and intense

Teacher: $\quad$ So that should have been in the adjective side of the box. Another one? 
This discussion, in contrast to the earlier episodes which were opening up discussion of the effect of word choice on character description, addresses a right-wrong answer. The teacher's recognition that the confusion needed to be discussed is significant, but also she handles the clarification skilfully by not getting distracted into lengthy grammatical explanations or definitions, but by quickly focusing thinking on the naming of body parts and the describing of those body parts, reflecting the grammatical function of the nouns and adjectives here. She consolidates the understanding with a follow-on interaction in similar vein, and then the students return to the task.

\section{$\underline{\text { Justification of choices }}$}

This code represents data segments where the teacher invites students to explain and justify either their own linguistic choices in their own writing, or in another text or opens up new possibilities to help with justification of choices. Frequently, this involved probing understanding of a particular linguistic choice by asking the student to provide examples:

Student: I can use appropriate words

Teacher: Tell me what you mean by appropriate words?

Student: Olden day words

Teacher: Any examples?

or by pushing for more explanation of a rather generalised statement:

Teacher: Why do you think the writer has chosen to do that?

Student: To make it more impactful

Teacher: What impact though? What impact do they want?

Student: You could use a short sentence to be really dialogic.

Teacher: What do you mean 'really dialogic'?

Justification of choices also included those interactions where the teacher was prepared to challenge a linguistic choice made by a student. In another of the episodes exploring how character is conveyed through noun phrases, one student explains how in her own character description she has changed 'dark brown eyes' to 'penetrating eyes, the colour of chocolate'. The teacher picks up the adjective choice, 'penetrating', and comments 'Most of us would think of chocolate as nice and smooth and something we would want, maybe not as penetrating?' inviting the student to think more about the appropriacy of the choice.

These interactions, whilst being prepared to question a particular choice, still left the student with ownership of the final decision. In the extract below, the teacher invites the writer to think about justifying whether the noun phrases is best pre-modified or post-modified, and the choice of a repeated word:

Student: $\quad$ A lady with long dark hair and long fingers

Teacher: I can see how you've used adjectives to add to your noun to make a noun phrase but they're both pre-modification, aren't they, before the noun? Perhaps you could put one before and one after. Do you think long in both is the best choice of words? Did you go for repetition on purpose, or did that just happen to be the two words that you came up with? As a writer, if you make a decision to use repetition, that's fine. If you just thought long would do, I think you need to think about what you could use instead of long the next time. 
The discussion of the repetition of 'long' shows this teacher challenging whether the repetition is deliberate or accidental, inviting the student to justify the choices made, but still leaving the student the freedom to make the decision.

One more unusual example of justification of choices occurred in the teacher's task instructions regarding a peer feedback activity. The students were asked to read each other's writing and give feedback on what they thought were the 'best bits' and 'why'. The teacher then suggested they should model their peer talk on her own class talk with them:

Teacher: Question each other like I question you? Why have you chosen the word 'small'? Why have you written blue book, not navy?

\section{Clear Focus}

As noted earlier, the pedagogical principles which underpinned this intervention emphasised the importance of talk in developing metalinguistic understanding of the relationship between grammatical choices and their specific contextualised effects in a written text. Dialogic metalinguistic discussion was more frequently facilitated when there was a clear focus for discussion, supporting students in directing their talking and thinking towards a particular purpose. Many of the data segments in this code were teacher instructions which preceded a period of pair or group talk, often interspersed within whole class discussion.

In some instances, the clear focus was achieved by narrowing the topic to be discussed so that student thinking was directed very precisely towards a particular metalinguistic conversation. In the first segment below, the teacher acknowledges the common tendency to equate description in writing with the use of adjectives, but the talk focus in this lesson is on well-chosen nouns and verbs. So her task instruction redirects to them 'alternative ways', and reinforces this with the 'banning' of discussion of adjectives. In the second segment, from a different teacher but addressing the same topic, the teacher narrows the focus by drawing attention to the fact that in the descriptive passage they had been reading there were more nouns than adjectives:

First task is - we've been learning to use adjectives for most of primary school to describe. What have we been looking at as alternative ways to describe characters? 30 seconds to talk amongst yourselves, the banned word in adjectives.

With your Talk Partner, talk about one thing you have learned - remembering that we can see that in this extract the nouns outnumber adjectives...

Elsewhere the clear focus was enhanced by a combination of narrowing, plus questioning which opens up a metalinguistic conversation. In the first segment below, students are looking at a Powerpoint slide which has colour-coded nouns and adjectives, and the teacher's question invites metalinguistic reasoning about word classes. In the second, the class are considering Morpurgo's use of a subject-verb inversion at a particularly dramatic moment in the narrative, and the teacher re-focuses their attention to the reversal and the position of the verb within questions which invite open-ended discussion about Morpurgo's linguistic choice:

Some words are underlined in red and some in blue. In pairs, work out why? 
But he didn't write it like that... think about these questions: Why do you think he changed it around? Why have we got the verb first? What effect does it have on the reader? Talk about in pairs.

Another way that a clear focus was achieved was through stating very explicitly what the expected outcomes of the discussion would be:

- First of all we're going to focus on the crypt [goes through each of the descriptions]. I'm going to give you one minute to discuss the different ways the crypt has been described and I want you to tell me what impact, what effect has this had on you as reader?

In one data segment, the teacher establishes a clear focus for talk by drawing out the linguistic choices possible in a particular example, and explicitly modelling two of the possibilities. This supports the metalinguistic discussion by underlining that the talk is not about working towards 'right' answers, but about understanding the effects of different choices:

I I'm going to read a few of these out and I want you to think about what might be the effect of these. Let's look at the first one. "Her fingers, long, white and dancing" was my noun phrase. You could have said "Her long, white, dancing fingers" if you wanted to - you can put those three blue adjectives in front of your noun. What would be the effect of writing it this way: "her fingers, long, white and dancing"? Have a conversation on your tables.

\section{Less Dialogic Metalinguistic Discussion}

Unclear focus for discussion

Data segments coded as representing an unclear focus for discussion were those where students seemed to struggle to respond to the discussion prompt or questions as they were unsure what was required of them. Some examples of this were simply questions or instructions which were too vague or open-ended for students to engage with, as those below:

Second piece of text, who can tell me something about it?

Which do you think is more interesting, the DVD or the story?

- Have a think of everything you've learned and see if you can apply it to this picture of the dragon.

This kind of lack of clarity could occur in any lesson or subject, and is not particularly linked to metalinguistic talk. However, the majority of examples coded in this group did relate to the fact that the intervention was targeted on developing students' metalinguistic understanding of the effect of grammatical choices in writing. In some cases, the lack of focus seemed to stem from the teachers' genuine attempts to make these grammar-writing connections, but not quite succeeding in articulating the question clearly. For example, in the segment below, the teacher was trying to elicit understanding of how noun phrases can support 'show not tell' in character description, but the question is framed in such a way that students were left floundering:

What have we learnt about words, in terms of description of characters? What have we learnt about words?

In another example, from a different teacher, the students were again left unsure about what they were being asked to consider. The teacher was trying to prompt discussion of abstract nouns as alternatives to adjectives, but the opening question suggests this might be a literal comprehension question about the 
dragon's attributes. The follow-on statements obfuscate further what the question is addressing, making a grammatical reference to adjectives, but then seemingly still pursuing the dragon's attributes:

What else does the dragon have? We're not describing the adjectives... we're not saying the dragon has large webbed green wings, we're saying the dragon has strength, the dragon has wisdom... power...etc"

Perhaps unsurprisingly, a student gives the answer, 'The dragon has magical powers', indicating that she thought the question was a comprehension question not a metalinguistic discussion one.

In other examples, teachers were over-focused on grammatical terminology without any real substance to the discussion; almost a pseudo-metalinguistic conversation. This is evident in the two segments below. In the first, the talk about tenses is unfocused: there is no clarity about what the tense problem was, and the description of tenses being back to front in some places is puzzling. In the second example, the question is so open-ended, it's hard to know what an 'approved' answer might be:

Teacher: What did your partner tell you you could do to improve your writing?

Student: My tenses.

Teacher: Your tenses, were they back to front in some places? That's a good thing you can improve on.

Teacher: If I'm trying to create a picture in the reader's mind, which word classes am I going to use a lot of?

To an extent, some of the challenges teachers faced in these examples of poorly focused discussion prompts reveals their difficulty mastering the expectations of the pedagogy underpinning the intervention. It was also evident that an unclear focus was often linked to uncertainty in grammatical subject knowledge. This had the consequence that grammatical terms were often used to initiate metalinguistic discussion but the examples offered, or accepted, by the teacher were incorrect, and thus the students may have been acquiring metalinguistic misunderstandings:

Teacher: $\quad$ Tell me about dragons. Don't give me adjectives, give me nouns. OK, so shades of different blue?

Student: Purply blue?

Student: The dragon's wings glowed.

Student: They have butterfly wings

Here the teacher frames the talk around nouns, not adjectives, but then ask for shades of blue which inevitably leads to suggestions of adjectival synonyms for blue. This leads to offers of more description of the dragon, one with a verb (glowed) and the second with a noun acting adjectivally (butterfly). Subject knowledge problems with nouns and noun phrases are also evident in this next example:

Teacher: Can you think in terms of noun phrases, how we can describe, not use adjectives, but how we can describe the dragon. Was the dragon a small dragon?

Student: No

Teacher: Remember show not tell, we're going to do the show, not tell.

Student: The dragon was colossal . 
Teacher: Colossal - I like that word but let's start off with 'The dragon shows his strength.' (writes this on the board) Where's the noun?

Student: Dragon

Teacher: and?

Student: Strength

Teacher: How does he show his strength? Remember when we talked about the horse that galloped and leapt. What kind of words can we use to make the noun phrase, to post modify the noun?

Student: bellowed

Teacher writes: The dragon showed his strength as he bellowed. What did he bellow?

This pattern of an unclear focus for discussion created by grammatical subject knowledge problems was a common one in this code. It reflects teachers genuinely engaging with the pedagogical demands of the intervention, which ironically in these cases had the effect of limiting the quality of metalinguistic discussion, rather than strengthening it.

\section{Too much teacher talk}

This code encompasses both situations where the teacher was highly-controlling of the talk, creating little dialogic space for the students to use talk to support metalinguistic thinking, and where the teacher simply talked too much, reducing students' opportunities for talk. The observation data in the transcripts often referred to the occurrence of too much teacher talk as a comment on the whole, or part of the lesson:

- Teacher tends to control responses and move discussion on without fully exploring or making explicit the grammar-writing connection.

- The first 25 minutes of the lesson were teacher-led with minimal student contribution.

Dominates discussion and rarely gives students space to think for themselves. Their responses are very limited (often one word) and hard to hear.

The staged activities on the plan have been conflated and dominated by the teacher with the effect that they don't really have space to think for themselves.

One tendency on data segments coded as too much teacher talk was for the teacher to answer his or her own question, either directly as in the example below, where two questions are asked and answered in one speech turn:

Teacher: Do they emphasise different things and create different effects? Yes they do. Which one is more dramatic? The first one, it has a better effect.

Or the teacher answers her own question more indirectly, allowing for an interaction sequence to occur before she provides the answer she was looking for:

Teacher: How can we, how would you, how could the writer make it better, do you think?

Student: More vocabulary.

Teacher: More vocabulary, yes.

Student: Not repeating the same words.

Teacher: Not repeating the same words. That goes back to vocabulary doesn't it?

Student: [Unclear] ... about the name of the Lady of the Lake.

Teacher: $\quad$ But I think her name might be 'The Lady of the Lake', but you could refer to her in 
different ways, couldn't you? So that you're not repeating The Lady of the Lake, The Lady of the Lake...

Student: More adjectives...

Teacher: OK...

Student: Use commas a bit more.

Teacher: Use commas a bit more...OK. Think back to what Malorie Blackman said about using short sentences to build up suspense. Are there many short sentences in there?

Students: No...

Teacher: Did you feel like it was suspenseful? Did you feel like...

Students: No...

Teacher: So you want more detail, more information.

In this sequence, the teacher's repetition of the student's answer is an indirect way of signalling that it is not the answer required. The students' responses become increasingly random, trying out any points they know may relate to 'good' writing, including using adjectives and remembering to use commas. When the teacher finally concludes this sequence, there is little evidence that students have gained any understanding of how to make this piece of writing better, or from a metalinguistic point of view, what might have helped to establish more detail and information.

In other instances, the teacher controlled the discussion not so much by providing the answers outright but by strongly cueing the response, often using tone of voice as part of the cueing. This is evidenced in the two examples below:

Teacher: What have you learned today?

Student: That nouns can outnumber adjectives

Teacher: always? -

Student: No

Teacher: or is it that you can make better choices

Student: you can make better choices. (led)

Teacher: We've always been told that adjectives are the most powerful use of language there is - do you think that's right?

Student: $\quad$ No (strongly led by the teacher)

In some instances, the teacher laboured a point, allowing the discussion to continue rather purposelessly for too long, without a clear point being developed. We can see this in the extract below which is prompted by Morpurgo's description of Guinevere as 'a girl - no, rather a woman'. The sequence opens with one student's very literal interpretation of Morpurgo's description:

Student: When it says she was a girl, no, rather, a woman, it makes you think she was a young woman.

Teacher: Yes, we were starting to speak about this earlier. The writer has said there was a girl so straight away in your mind you're imagining this girl. Then it changes it to, 'rather, a woman' so we think 'one minute ago she was a girl but now he's confused, now she's a woman'. What impression is giving us of her?

Student: She's quite grown up? 
Teacher: You think maybe she's quite grown up? He's saying she's a girl. One minute he's saying she's a girl then he's saying no, she's actually a woman. She was a girl, now she's a woman. What does that tell us about her?

Student: She's a very young woman. She doesn't look old.

Teacher: Maybe she's quite young. Maybe she doesn't look the age she is.

Student: She might be a teenager.

Teacher: She might be a teenager. Or maybe the impression that was given is she is quite young. So even though she's a woman, you can see she was a girl. She's not got that strong presence like Nimueh has, standing there shaking. She was a girl, now she's a woman.

Even by the end of this sequence, it remains unclear what point the teacher was hoping to explore or establish through the discussion. The teacher's talk turns are significantly longer than the students', and the students' contributions are rather low-level responses to her questions. (Although the student who suggests Guinevere might be a teenager may have been attempting a compromise between girl and woman!)

The interaction patterns reflected in this section of the data are not new and echo numerous research studies over a long period which have illustrated that some teachers control and dominate classroom talk too much (Howe and Abedin 2013). Unlike those interaction sequences identified as lacking a clear learning focus, where the teachers' subject knowledge of grammar and the pedagogy of the intervention seemed to be playing a part, the prevalence of teacher talk exemplified in this code seem more related to more general pedagogic practices and teacher style, and do not appear to have any particular connection to the metalinguistic focus of the talk.

\section{Missed opportunity for learning}

This code relates very specifically to the nature of the intervention and the research focus on metalinguistic understanding. In these data segments, the teachers missed an opportunity to develop rich dialogic metalinguistic discussion from a comment arising from the spontaneous flow of interaction. In particular, segments coded here linked to the goal of the intervention to make meaningful connections between a particular grammar feature and its effect in writing.

One repeated cause for a missed opportunity was the tendency of teachers to signal approval for something a child had written, but not to develop that into an opportunity to explain why, or solicit students' own decision-making. Three examples from three different teachers are below:

- 'I looked up and saw the surface of the lake shiver.' I really like that sentence.

口 'Sir Pent was tall, his skin pale and smooth.' I like that.

口 I like 'burly' - that was my favourite word in there.

These missed opportunities were almost always in the context of a positive and supportive classroom environment, looking to reinforce and praise students' endeavours, but without accompanying explanation or discussion, it is unlikely that students will have increased their metalinguistic understanding of the relationship between a linguistic choice and its effect on a particular reader (in this case, the teacher). Indeed, in this last example, the learning focus for the episode was on well-chosen nouns, so not only did students not necessarily know why the teacher liked burly, but they may have been misled into thinking it was a noun.

In another data segment, the teacher is particularly pleased with the writing of one student who is one of the lower-attaining students in the class. In order to celebrate his success, she interrupts her teaching to 
invite him to share is sentence with the rest of the class. She is effusive about the quality of this sentence, and is giving Jason important positive reinforcement. However, there is no explanation of why she thinks this sentence is so praiseworthy, so the opportunity to link a grammatical choice with effectiveness in writing is missed. The sentence is a minor sentence, which may also have led some students to misunderstandings about what constitutes a sentence.

Teacher: I am going to deviate just a little from my lesson plan for a moment because we have had one of those absolute wow moments and I'm deviating because it is Jason...

Jason: (reading his writing) Not knowing what mysterious events await him.

Teacher: Not knowing what mysterious events await him. That is the most brilliant sentence and quite stealable. I think that's something I'll be using. I can use that in my story and I certainly will.

Other missed opportunities for learning arose when the teacher closed an interaction sequence at the point it would have been most valuable to open up discussion. In the sequence below, the class are discussing Morpurgo's description of Guinevere. The teacher leads them through a strongly cued sequence exploring how the nouns describing Guinevere are modified by adjectives, and the children show that they can locate the adjectives which describe each noun. But this is a fairly unchallenging level of activity, which might have been an appropriate initial sequence to ensure all the students had grasped this. The real metalinguistic learning might have occurred in the next sequence, where the teacher could have invited the students to consider how Morpurgo's specific descriptive choices established Guinevere's character. Instead, she closes the sequence by making the point about Show not tell, with no exploration of whether students have really understood it:

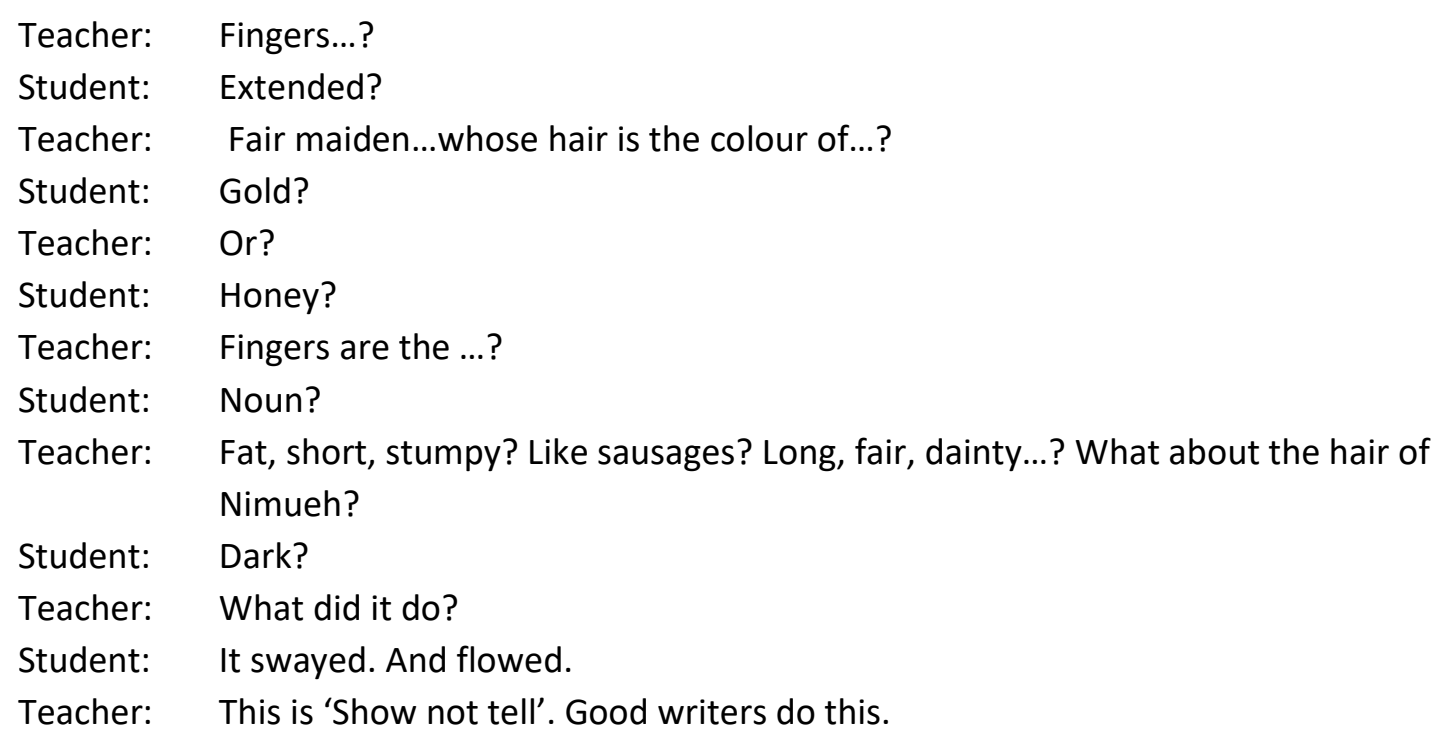

Elsewhere, missed opportunities arose when a student's response, with potential for further elaboration or discussion is passed over. In the sequence below, the class are discussing Morpurgo's use of a subject-verb inversion. The teacher uses an open question to initiate a meaningful discussion, and gets two responses which both had dialogic metalinguistic discussion opportunities. The first response indicates that one student has misunderstood the subject-verb inversion as the use of a passive: a not unreasonable confusion because the move from active to passive also involves a subject-object reversal. The student's response might have been a good chance to clarify this misunderstanding, although it also possible that in this context the teacher made a pedagogic decision not to dwell on this at the expense of the key learning in this episode. However, the second response offered is ripe for further exploration - what did the student 
mean? How did the subject-verb reversal draw attention to Arthur's emotions? What were these emotions? But the teacher appears to pass over both of these responses and move onto another question:

Teacher: $\quad$ So the verb is in front, but normally we have it after the subject. Why do you think the writer inversed, changed this around?

Student: $\quad$ To make it passive

Student: To bring out Arthur's emotions

Teacher: What about us as the reader? How do we read this sentence? How does it sound to you?

In general, a missed opportunity was much more likely to occur in positive classroom environments and in interaction sequences which were set up to foster dialogic metalinguistic discussion. In contrast to those episodes where there was too much teacher talk or an unclear focus for discussion, many of the data segments in this category appear to reflect teachers engaging with the principles of the pedagogy, and on a trajectory of development which could, with only minimal adjustment, lead to more genuinely dialogic metalinguistic conversations.

\section{DISCUSSION}

The findings from the data analysis point to three theoretical strands which inform our understanding of how dialogic classroom talk can foster the development of metalinguistic understanding in relation to writing. Firstly, the data suggests there is an important place for metalinguistic talk about writing in helping students recognise the inter-relationship of form and meaning in writing. Secondly, the analysis signals the significance of teachers' skills in managing dialogic classroom talk as one key pedagogical strategy for developing metalinguistic decision-making in writing. Finally, the data highlights how teachers' own grammatical subject knowledge influences and constrains their capacity to manage dialogic metalinguistic talk about writing.

\section{Learning how to mean}

The general principle that learning language is about learning how to mean is central to Hallidayan thinking (2004) and a not unfamiliar theoretical argument. In the context of writing, this involves writers in shaping text to satisfy their own authorial intentions, at the same time as being attentive to the needs of the implied reader, and the socially-shaped expectations of that genre of writing. We would argue that metalinguistic talk is pivotal to the development of this understanding because it makes often covert decision-making available for reflection and argument. If metalinguistic knowledge is characterised by being 'verbalisable' (Roehr 2008, 179), then dialogic metalinguistic discussion creates the opportunity for that verbalisation. The classroom talk coded as Justification of Choices is a particularly clear example of the encouragement of this verbalisation. The teachers encouraged students to articulate their writing choices, and to expand and elaborate upon them. This talk makes visible, and accessible for scrutiny, the thinking behind textual creation, and may well be supporting young writers in bringing to the surface half-formed or subconscious choices made. Potentially, in this way, for the individual writer, implicit choices are rendered explicitly available for reflection. Moreover, the teacher's management of dialogic talk in a writing classroom within a community of writers facilitates the development of shared understandings, often arising from a writing decision made by one student. It is noticeable in the data how teachers frequently use one student's writing or justification as the springboard for further discussion which includes other students. 
Equally, although the analysis draws out Missed Opportunities for Learning as one aspect of less dialogic metalinguistic discussion, it was nonetheless often found in positive interaction sequences which were open-ended and exploratory. Indeed, in some cases, the missed opportunity only arose because the preceding talk had opened up metalinguistic thinking in a dialogic way, but it was not followed through. From a pedagogical perspective, this points to a potential for growth in the teachers' capacity to manage metalinguistic talk: just as research on dialogic questioning has repeatedly urged teachers to allow more wait time in questioning sequences, so this research urges teachers to become attentive to the rich opportunities for extending metalinguistic discussion that students' responses afford. Metalinguistic conversations in the writing classroom are thus enabled to become the foundation for learning how to mean in writing. Crucially, they bring together the dialogical problem spaces of what to say and how to say it as complementary, reciprocal spaces of learning how to mean: rather than dichotomous, as in Bereiter and Scardamalia's (1987) model.

\section{The significance of teachers' management of dialogic metalinguistic talk}

The data reveal that teachers' management of dialogic metalinguistic discussion varies in its effectiveness, but also that 'dialogic/less dialogic' was rarely a simple characteristic of the teacher's pedagogic style. Rather, for most teachers observed, there were aspects of dialogic or less dialogic talk occurring within the lesson, and often even within an interaction sequence. It is important to remind ourselves here that in any lesson, a teacher is making a myriad of decisions, often instinctively, ranging from behaviour management to high-level learning decisions. Our analysis focuses very closely on one small strand of this pedagogic repertoire of the teacher, and it is likely that any micro-analysis such as this will always find aspects that could be improved. Given that more data segments were coded as dialogic than less dialogic, and given that Missed Opportunities for Learning was a category which seems to indicate potential growth points in the management of dialogic metalinguistic talk, the analysis arguably indicates that many of these teachers were successfully leading classroom metalinguistic talk about writing: a complex, high-level topic and one which is not a standard practice in many classrooms.

The finding that there was a common tendency for teachers to talk too much is not new, as noted earlier, and it seems that changing deeply embedded habits of classroom discourse, and moving from monologic to dialogic discourse patterns is hard. And yet the data provides good evidence of interaction sequences which do just this. When teachers control the talk too heavily, they close down thinking and limit the opportunities afforded by metalinguistic discussion: as some of our data segments illustrate. But likewise, when the talk is well-managed, it fosters metalinguistic thinking: purposeful reflection on decision-making in writing. Research has already asserted the importance of thinking in writing, but has tended to be strongly oriented towards the benefits of strategy instruction which focus on better regulation of the writing process (as for example in Graham's, 2006, Self-Regulated Strategy Development). It is thus very much targeting a cognitive process; indeed, Kellogg's (2008) argument that development in writing involves gaining control over cognitive processes seems to reinforce this. However, metalinguistic discussion is not concerned simply with managing the writing process, but with developing understanding of how meaning is shaped in written texts and fostering young writers' awareness of the repertoire of choice available to them as meaning-makers. As such it is a social process as much as a cognitive process, framed by socially shared understandings (and sometimes misunderstandings) within the classroom as a writing community. Moreover, well-managed metalinguistic talk about writing gives students ownership of the decisions they make in writing, and acts as a powerful counter to pedagogic practices which, usually unwittingly, foster formulaic, reproductive understandings of what is valued in writing. The evidence in the data of teachers skilfully challenging and questioning students about their writing choices, but also handing back the final decision to the authors allows for ownership rather than compliance. It rebalances the co-authoring 
relationship in the classroom described by Prior $(2006,58)$ from one where the teacher is a dominant author, to one where that dominance is less powerfully exercised.

\section{How grammatical subject knowledge shapes classroom metalinguistic talk}

Concerns about weaknesses in teachers' grammatical subject knowledge have been noted for several decades and across, predominantly Anglophone, jurisdictions. Our own previous research has signalled the affectivity of teachers' beliefs about grammar (Watson 2012, 2015), and the importance of both content and pedagogical knowledge of grammar (Myhill et al. 2013). Grammatical subject knowledge is not limited to being able to name and identify grammatical structures, but also to the pedagogical subject knowledge which facilitates enabling student learning about grammar. The analysis offered here illustrates specifically how weaknesses in grammatical subject knowledge can influence the quality of dialogic metalinguistic discussion.

Many of the interaction sequences coded as Unclear Focus for Learning were grounded in a subject knowledge issue. Sometimes this related to the teacher's efforts to be true to the principles of the intervention to develop explicit talk about grammar choices in writing, leading to the framing of questions which were too generalised to stimulate focused metalinguistic discussion, particularly vague questions about word classes or sentences in general. More commonly, however, the unclear focus was a consequence of teachers' problems with accurately identifying the grammatical feature. The intervention focus on noun phrases as a potential tool for character description made visible numerous confusions over the classification of nouns, adjectives and verbs, and with the noun phrase itself as a structure. This led to interaction sequences where the learning focus was unclear because an initiation question suggested the focus was on nouns or noun phrases, but subsequent utterances used examples which were adjectives or complete sentences. Likewise, some of the Missed Opportunities for Learning were when a student revealed a grammatical misunderstanding but the teacher did not pursue this because of lack of confidence in his/her ability to handle the misunderstanding, or because the misunderstanding was not noticed.

The intervention teaching materials focused on noun phrases and verbs, and on subject verb inversion, thus drawing attention to syntactical elements of the sentence. However, the data indicates the strong tendency of teachers to orient the discussion to lexical choice, at the level of the word. The interaction sequences relating to the noun phrase frequently became word choice discussions, and the lesson on subject verb inversion proved the most challenging lesson in the intervention for the teachers because it required syntactical, rather than lexical, knowledge. Teachers found the concept of the Subject hard to explain, and because the Morpurgo examples were sentences which included prepositional phrases and non-finite clauses, there was further confusion caused by their mobility within the sentence. It is noticeable that our data has relatively few extended interaction sequences from this lesson because many teachers cut the discussion short, or followed exactly the wording of the support materials. This may be because they were aware of their lack of confidence with this topic. A test of teachers' grammatical knowledge prior to teaching the intervention confirms that word class grammatical knowledge is stronger than syntactical knowledge, and this plays out in the metalinguistic discussions observed. Without secure grammatical subject knowledge, the dialogic development of metalinguistic talk about writing will always be limited.

\section{Conclusion:}

Coleridge described writing as 'the ordeal of deliberate choice' and this paper has focused on how teachers' management of classroom talk can help young writers understand the deliberate choices available to them. It has drawn attention to the value of dialogic metalinguistic talk in nurturing students' understanding of a repertoire of choices and the various effects those choices have within a text. At the same time, it has 
offered a detailed analysis of teachers' orchestration of metalinguistic talk about writing, how it can constrain or enable metalinguistic thinking, and how limitations in teachers' own grammatical knowledge mediate how the talk is managed. What it has not shown is the nature of students' development in metalinguistic thinking, both about grammatical concepts and, more significantly, about linguistic decisionmaking in writing. Nor has it explored how developing metalinguistic understanding translates into students' written texts. Nonetheless, the paper advances our understanding of metalinguistic talk about writing as it occurs in the shared spaces of classroom discourse, and the enabling role of the teacher in establishing metalinguistically aware communities of writers.

\section{REFERENCES}

Alexander, R. 2008. Towards Dialogic Teaching: Rethinking Classroom Talk. 4th ed. York: Dialogos.

Barrs, M., and V. Cork. 2001. The Reader in the Writer: The Influence of Literature upon Writing at KS2. London: Centre for Literacy in Primary Education.

Becker, A. 2006. "A Review of Writing Model Research Based on Cognitive Processes." In Revision: History, Theory and Practice, edited by A. Horning and A. Becker, 25-49. West Lafayette, Indiana: Parlor Press.

Bereiter, C., and M. Scardamalia. 1987. The Psychology of Written Composition. Hillsdale, NJ: Lawrence Erlbaum.

Bialystok, E. 1987. "Influences of Bilingualism on Metalinguistic Development." Second Language Research 3: 154-166.

Bialystok, E., and E. B. Ryan. 1985. "Toward a Definition of Metalinguistic Skill." Merrill-Palmer Quarterly 31 (3) 229-251.

Britton, J. 1983. "Writing and the Story of the World." In Explorations in the Development of Writing: Theory, Research, and Practice, edited by B. M. Kroll and C. G. Wells, 3-30. New York: Wiley.

Bruner, J. 1983. Child's Talk: Learning to Use Language. Oxford: Oxford University Press.

Carter, R., and M. McCarthy. 2006. Cambridge Grammar of English. Cambridge: Cambridge University Press.

Chinn, C., A. O'Donnell, and T. Jinks. 2000. "The Structure of Discourse in Collaborative Learning." The Journal of Experimental Education 69: 77-89.

Corden, R. 2000. Literacy and Learning through Talk: Strategies for the Primary Classroom. Birmingham: Open University Press.

Deane, P., N. Odendahl, T. Quinlan, M. Fowles, C. Welsh, and J. Bivens-Tatum. 2008. Cognitive Models of Writing: Writing Proficiency as a Complex Integrated Skill. Princeton, NJ: Educational Testing Service. Accessed 04.12.15. http://www.ets.org/Media/Research/pdf/RR-08-55.pdf

Galbraith, D. 1999. "Writing as a Knowledge-Constituting Process." In Knowing What to Write: Conceptual Processes in Text Production, edited by M. Torrance and D. Galbraith, 79-97. Amsterdam: Amsterdam University Press.

Gillies, R. 2015 "Dialogic Interactions in the Cooperative Classroom." International Journal of Educational Research. Elsevier. Accessed 04.12.15. http://dx.doi.org/10.1016/j.ijer.2015.02.009

Gillies, R., K. Nichols, G. Burgh, and M. Haynes. 2012. "The Effects of Two Meta-Cognitive Questioning Approaches on Children's Explanatory Behaviour, Problem-Solving, and Learning during Cooperative, Inquiry-Based Science." International Journal of Educational Research 53: 93-106.

Gombert, E. J. 1992. Metalinguistic Development. Hemel Hempstead: Harvester Wheatsheaf.

Graham, S. 2006. "Strategy Instruction and the Teaching of Writing: A Meta-analysis." In Handbook of Writing Research, edited by C. A. MacArthur, S. Graham, and J. Fitzgerald, 187-207. New York: The Guilford Press.

Halliday, M.A.K. 2004. "Three Aspects of Children's Language Development: Learning Language, Learning through Language, Learning about Language". In J.J. Webster (ed.), The Language of Early Childhood: pp 308-326, Ch. 14. New York: Continuum

Howe, C., and M. Abedin. 2013. "Classroom Dialogue: A Systematic Review across Four Decades of Research." Cambridge Journal of Education 43: 325-356.

Janks, H. 2009. "Writing: A Critical Literacy Perspective." In The Sage Handbook of Writing Development, edited by R. Beard, D. Myhill, M. Nystrand, and J. Riley, 126-136. London: Sage. 
Jones, S. M., D. A. Myhill, and T. C. Bailey. 2013a. Grammar for Writing? An Investigation into the Effect of Contextualised Grammar Teaching on Student Writing. Reading and Writing 26 (8): 1241-1263.

Jones, S. M., D. A. Myhill, A. Watson, and H. E. Lines. 2013b. "Playful Explicitness with Grammar: A Pedagogy for Writing." Literacy 47 (2): 103-111.

Kellogg, R. 2008. "Training Writing Skills: A Cognitive Development Perspective." Journal of Writing Research 1 (1): 1-26.

Littleton, K., and C. Howe. 2010. Educational Dialogues: Understanding and Promoting Productive Interaction. Abingdon: Routledge.

Mercer, N. 2000. Words and Minds: How we Use Language to Think Together. London: Routledge.

Mercer, N., and K. Littleton. 2007. Dialogue and the Development of Children's Thinking: A Socio-cultural Approach. Abingdon: Routledge.

Micciche, L. 2004. "Making a Case for Rhetorical Grammar." College Composition and Communication 55 (4): 716-737.

Myhill, D. A. 2011. "The Ordeal of Deliberate Choice': Metalinguistic Development in Secondary Writers.” In Past, Present, and Future Contributions of Cognitive Writing Research to Cognitive Psychology, edited by V. Berninger, 247-274. New York: Psychology Press/Taylor Francis Group.

Myhill, D. A., and S. M. Jones. 2015 - in press. "Conceptualising Metalinguistic Understanding." Cultura y Educacion 27 (4)

Myhill, D. A., S. M. Jones, H. Lines, and A. Watson. 2012. "Re-Thinking Grammar: The Impact of Embedded Grammar Teaching on Students' Writing and Students' Metalinguistic Understanding." Research Papers in Education 27 (2): 139-166.

Myhill, D. A., S. M. Jones, and A. Watson. 2013. "Grammar Matters: How Teachers' Grammatical Subject Knowledge Impacts on the Teaching of Writing." Teaching and Teacher Education 36: 77-91.

Negro, I., and L. Chanquoy. 2005. "The Effect of Psycholinguistic Research on the Teaching of Writing." 11 Studies in Language and Literature 5 (2): 105-111.

Prior, P. 2006. "A Sociocultural Theory of Writing." In Handbook of Writing Research, edited by C. A. MacArthur, S. Graham, and J. Fitzgerald, 54-66. New York: The Guilford Press.

Reznitskaya, A., L-J. Kuo, A-M. Clark, B. Miller, M. Jadallah, R. Anderson, and K. Nguyen-Jahiel. 2009. "Collaborative Reasoning: A Dialogic Approach to Group Discussions." Cambridge Journal of Education 39 (1): 29-48.

Roehr, K. 2008. "Metalinguistic Knowledge and Language Ability in University-Level L2 Learners." Applied Linguistics 29 (2): 173-199.

Shanahan, T. 2006. "Relations among Oral Language, Reading and Writing Development." In Handbook of Writing Research, edited by C. MacArthur, S. Graham, and J. Fitzgerald, 171-183. New York: The Guilford Press.

Skidmore, D. (2000) "From pedagogical dialogue to dialogical pedagogy" Language and Education, 14(4): 283-296.

Skidmore, D. 2006. "Pedagogy and Dialogue." Cambridge Journal of Education 36: 503-514.

Wang, G. H., and S-D. Wang. 2013. "Roles of Metalinguistic Awareness and Academic Extensive Reading in the Development of EFL/ESL Academic Writing Skills." Journal of Arts and Humanities 2 (9): 47-55.

Watson, A. M. 2012. "Navigating 'The Pit of Doom': Affective Responses to Teaching 'Grammar'." English in Education 46 (1): 22-37.

Watson, A. M. 2015. “Conceptualisations of 'Grammar Teaching': L1 English Teachers' Beliefs about Teaching Grammar for Writing." Language Awareness 24 (1): 1-14.

Wegerif, R. B. 2011. "Towards a Dialogic Theory of How Children Learn to Think." Thinking Skills and Creativity 6 (3): 179-190.

Wilkinson, L. C., A. C. Wilkinson, F. Spinelli, and P. C. Chiang. 1984. "Metalinguistic Knowledge of Pragmatic Rules in School-AFge Children." Child Development 55 (6): 2130-2140. 